\title{
COMPOSIÇÃO FLORÍSTICA E ESTRUTURA DA COMUNIDADE ARBÓREA EM UMA FLORESTA ESTACIONAL DECIDUAL EM AFLORAMENTO CALCÁRIO (FAZENDA SÃO JOSÉ, SÃo DOMINGOS, GO, BACIA DO RIO PARANÃ)
}

\author{
Luciana Álvares da Silva ${ }^{1}$ \\ Aldicir Scariot ${ }^{1}$
}

Recebido em 05/11/2001. Aceito em 05/11/2002

\begin{abstract}
RESUMO - (Composição florística e estrutura da comunidade arbórea em uma floresta estacional decidual em afloramento calcário (Fazenda São José, São Domingos, GO, bacia do rio Paranã). A bacia do rio Paranã (Goiás e Tocantins) com 5.940.382ha, tem alta diversidade de fitofisionomias, incluindo a floresta estacional decidual sobre afloramento calcário, que ainda não foi estudada nesta região. Este trabalho objetivou o levantamento quantitativo da vegetação arbórea de uma floresta estacional decidual sobre afloramento calcário (1349'34"'S e 46 41'55" W; $478 \mathrm{~m}$ de altitude) na fazenda São José, São Domingos, GO. Foram demarcadas cinco linhas a intervalos de 100m, onde foram aleatoriamente alocadas 25 parcelas permanentes de $20 \times 20 \mathrm{~m}(1,0 \mathrm{ha})$. Em cada parcela foram amostrados todos os indivíduos com diâmetro à altura do peito (DAP) igual ou maior que $5 \mathrm{~cm}$, onde foram medidos o DAP e a altura, e identificadas as espécies. Foram amostrados 588 indivíduos (536 vivos e 52 mortos ainda em pé), pertencentes a 36 espécies, 31 gêneros e 21 famílias, com índice de Shannon 2,99 e Equabilidade 0,83. As principais espécies em valor de importância (VI), foram: Tabebuia impetiginosa (43,81), Aspidosperma pyrifolium (35,64), Luetzelburgia sp. (21,77), Commiphora leptophloeos $(18,79)$, Myracrodruon urundeuva $(15,79)$, Pseudobombax tomentosum (13,42), Combretum duarteanum (13,04), Luehea divaricata (12,24), Cabralea canjerana $(11,99)$, Ficus pertusa $(11,82)$, Jacaranda brasiliana $(11,68)$ e Aspidosperma sp. $(10,57)$ que juntas somaram $73,5 \%$ do VI total, enquanto as 24 espécies restantes somaram 26,5\%. Esta floresta é similar, em termos de diversidade, a outras áreas de afloramentos na região.
\end{abstract}

Palavras-chave - florística, fitossociologia, diversidade

\begin{abstract}
Floristic composition and structure of the tree community in a deciduous forest on a limestone outcrop in São Domingos, Goiás, Paranã river basin, Brazil). The Paranã river basin (States of Goiás and Tocantins, Brazil), with 5,940,382 ha, has many different plant physiognomies, including the deciduous forest on limestone outcrops which has not yet been studied in this region. In this paper we present the structure of the tree community of a deciduous forest on a limestone outcrop (13 49'34" S; $46^{\circ} 41^{\prime} 55^{\prime \prime} \mathrm{W}$ ) in São Domingos municipality, Goiás State, Brazil. Twenty-five plots of $20 \mathrm{~m} \times 20 \mathrm{~m}\left(400 \mathrm{~m}^{2}\right)$ were randomly placed on lines $100 \mathrm{~m}$ apart. Trees with $\mathrm{dbh}>5 \mathrm{~cm}$ were tagged, measured, and identified to species. In the phytosociological study, 588
\end{abstract}

1 Pesquisador da Embrapa Recursos Genéticos e Biotecnologia (Cenargen) - Parque Estação Biológico Final Av. W/5 Norte, C. Postal 02372, CEP 70770-900, Brasília, DF, Brasil (luciana.alvares@ zipmail.com.br; scariot@ cenargen.embrapa.br) 
individuals were sampled. A total of 36 tree species, belonging to 31 genera and 21 families were registered. The species with the highest importance value (IV) were: Tabebuia impetiginosa (43,81), Aspidosperma pyrifolium $(35,64)$, Luetzelburgia sp. (21,77), Commiphora leptophloeos $(18,79)$, Myracrodruon urundeuva $(15,79)$, Pseudobombax tomentosum $(13,42)$, Combretum duarteanum $(13,04)$, Luehea divaricata $(12,24)$, Cabralea canjerana (11,99), Ficus pertusa $(11,82)$, Jacaranda brasiliana $(11,68)$ and Aspidosperma sp. $(10,57)$. Together these make up $73.5 \%$ of total IV while the 24 remaining species constitute $26.5 \%$.

Key words - floristic, phytosociology, diversity

\section{Introdução}

A bacia do rio Paranã $\left(13^{\circ} 20^{\prime}-15^{\circ} 40^{\prime}\right.$ ', $46^{\circ} 35^{\prime}-47^{\circ} 30^{\prime} \mathrm{W}$ ) com 5.940.382ha, nos estados de Goiás e Tocantins, é um dos mais expressivos encraves de floresta estacional decidual do Brasil. Esta região é muito explorada para ampliação de áreas de pastagens, agricultura e exploração seletiva de madeira. O desmatamento resultou na formação de fragmentos (Scariot \& Sevilha 2000), geralmente dispersos na paisagem e com distintos níveis de perturbações antrópicas, causadas pela retirada de determinadas espécies madeireiras e pela pecuária, incêndios e caça.

A região tem alta diversidade de fitofisionomias, incluindo a floresta estacional decidual sobre afloramento calcário, que ainda não foi estudada nesta região. A ocupação atual da região é considerada média a alta, com destaques para a utilização de pastagens plantada e natural para pecuária extensiva e agricultura incipiente, ocorrendo ainda muita vegetação secundária tipo capoeira e exploração madeireira, especialmente de aroeira (Myracrodruon urundeuva) (IBGE 1995).

Atualmente ocorre um rearranjo espacial, após ocupação intensa, a partir dos anos 70, e principalmente na década seguinte, devido à imigração do sul e sudeste do país, quando ocorreu o auge de extração madeireira, que funcionou como requisito e sustento para a implantação de pastagens (Andahur 2001).

A bacia do rio Paranã é uma depressão entre os relevos do Planalto do Divisor São Francisco - Tocantins e o Planalto Central Goiano, desenvolvendo-se da porção centro-sul da região nordeste do Estado de Goiás para a porção nordeste, a qual abrange o município de São Domingos, onde foi desenvolvido o presente trabalho (IBGE 1995).

O processo de ocupação da paisagem resulta em mosaico de fragmentos florestais de diversas ordens de magnitude, espalhados e isolados, sendo a maioria deles pequenos, gravemente perturbados e localizados em áreas de baixa aptidão agropecuária (topografia acidentada, solos pobres, drenagem deficiente, etc.) (Bierregaard et al. 1992). Isto pode ser ainda mais agravado na bacia do rio Paranã, que é considerada como a última região disponível para expansão da fronteira agrícola no Estado de Goiás, portanto, passível ainda de sofrer impactos da ocupação com base na atividade de pecuária intensiva (Luíz 1998).

A floresta estacional decidual é caracterizada por apresentar duas estações climáticas bem definidas, uma chuvosa seguida de longo período seco, ocorrendo na forma de disjunções florestais e apresentando estrato dominante predominantemente caducifólio, com mais de $50 \%$ dos indivíduos despidos de folhagem no período desfavorável (Veloso et al. 1991). Ocorre em forma de manchas na região do Brasil Central, distribuídas pelos Estados de Minas Gerais, Goiás, Mato Grosso e Bahia (Rizzini 1979). Pode ser encontrada em solos desenvolvidos em rochas básicas de alta fertilidade (Terra Roxa Estruturada, Brunizém ou Cambissolos), em Latossolos Roxo e Vermelho-Escuro, de média fertilidade, em que ocorrem principalmente as Matas Secas SempreVerde e Semidecidual. A Floresta Estacional Decidual geralmente ocorre sobre solos de 
origem calcária, às vezes com afloramentos rochosos típicos, mas também pode ocorrer em solos de outras origens (Ribeiro \& Walter 1998). É considerada de relevante importância, em termos botânicos, por apresentar fisionomia e florística próprias (Rodrigues 1999; Ivanauskas \& Rodrigues 2000). A flora endêmica das florestas estacionais deciduais, localizadas em áreas calcárias, já começa a apresentar extinções locais no território nacional (Pereira et al. 1996).

Em estudo feito em área de afloramento calcário no Estado de Minas Gerais, Pedersoli \& Martins (1972) descreveram que vegetação ocorrente na superfície dos afloramentos é típica e talvez endêmica daquelas formações e verificaram que a maioria das espécies do estrato arbóreo perde as folhas no período da seca, que ocorre de junho a setembro. As espécies observadas em condição de solo litólico apresentam adaptações fisiológicas e/ou morfológicas, capacitando-as para resistirem à deficiência hídrica estacional como armazenamento de água em partes da planta, deciduidade, órgãos para absorção da umidade atmosférica ou de chuvas e outras (Rodrigues 1999).

$\mathrm{O}$ aquecimento e resfriamento diferencial provocam fraturas e diaclases no calcário que, sendo muito pouco atacado pela água, sofre, todavia, em presença do gás carbônico, grande dissolução feita pelas águas que abrem caminho facilmente através dessas gretas, infiltrando-se nelas, propiciando o acúmulo de húmus no local e favorecendo o surgimento de certas plantas, que se alojam nessas fendas (Pedersoli \& Martins 1972). Devido à exploração pelas fábricas de cimento, pela agricultura e pelo extrativismo madeireiro, a distribuição das florestas sobre afloramentos de calcário é cada vez mais restrita, sendo necessários estudos para compreensão de sua dinâmica e importância na manutenção da diversidade, e assim adotar uma política de conservação desses ecossistemas (Ramos 1989). A singularidade, o nível de endemismos e o desconhecimento dessa vegetação caracterizam a importância das mesmas para a conservação, aliadas ao fato de serem pouco representadas em unidades de conservação.

Apesar da escassez de dados, é importante entender a dinâmica dos fragmentos e as consequiências das perturbações causadas pela extração de madeira e fragmentação, e assim, conceber regimes de manejo e uso da terra que mantenham a biodiversidade para melhor desenhar e manejar as reservas, orientando as políticas de conservação (Whitmore 1997). É, portanto, necessário o desenvolvimento de sistemas de uso sustentável da terra em florestas secas, baseados no conhecimento detalhado da estrutura e funcionamento da floresta e resposta à perturbação (Maass 1995).

Este trabalho objetivou o levantamento quantitativo em um fragmento de floresta estacional decidual sobre afloramento calcário, na região da bacia do rio Paranã (Goiás e Tocantins), para caracterizar a vegetação e assim fornecer subsídios para estratégias de conservação e manejo das florestas estacionais deciduais do Brasil Central.

\section{Material e métodos}

O clima da região pode ser classificado, segundo Köppen, como do tipo CW, com médias anuais de temperatura de $24^{\circ} \mathrm{C}$, pluviosidade de $1.500 \mathrm{~mm}$ e umidade relativa de $60 \%$. A região da bacia do rio Paranã é circundada por relevos de planaltos e chapadas, constituindo uma região deprimida com altitudes que oscilam entre 400 e $600 \mathrm{~m}$, alongada no sentido norte-sul (IBGE 1995).

Este trabalho foi realizado na fazenda São José, município de São Domingos, GO (bacia do rio Paranã). O fragmento, com aproximadamente $300 \mathrm{~m}$ de largura e $600 \mathrm{~m}$ de comprimento, localiza-se entre as coordenadas $13^{\circ} 49^{\prime} 34^{\prime \prime} \mathrm{S} \mathrm{e} 46^{\circ} 41^{\prime} 55^{\prime \prime} \mathrm{W}$ e $478 \mathrm{~m}$ de altitude que, segundo Veloso et al. (1991), pode ser classificado como floresta estacional decidual (mata seca), e ocorre sobre área de 
afloramento calcário. A área de estudo foi selecionada, após uma busca pela região, por apresentar-se bem preservada, ter fácil acesso e pela permissão para se trabalhar na área. Apesar desse fragmento estar bem preservado, observa-se marcas recentes de extração de madeira, principalmente aroeira (Myracrodruon urundeuva) e ipê (Tabebuia impetiginosa).

Foram demarcadas cinco linhas paralelas, a intervalos de $100 \mathrm{~m}$, atravessando a área de uma extremidade a outra, onde foram alocadas aleatoriamente 25 parcelas permanentes de $20 \times 20 \mathrm{~m}\left(400 \mathrm{~m}^{2}\right.$; total de 1,0ha amostrado) (Fig. 1). Devido à dificuldade de se fixar estacas na rocha, em algumas parcelas optou-se por marcação na pedra, com tinta vermelha, para delimitar a área. Foi fixada uma estaca por parcela, identificando a linha e o número da parcela, para facilitar medições futuras.

\begin{tabular}{|c|c|c|c|c|}
\hline $\mathbf{A}$ & B & C & D & $\mathbf{E}$ \\
\hline 1 & 11 & 17 & 32 & 46 \\
\hline 2 & 12 & 18 & 33 & 47 \\
\hline 3 & 13 & 19 & 34 & 48 \\
\hline 4 & 14 & 20 & 35 & 49 \\
\hline 5 & 15 & 21 & 36 & 50 \\
\hline 6 & 16 & 22 & 37 & 51 \\
\hline 7 & & 23 & 38 & 52 \\
\hline 8 & & 24 & 39 & 53 \\
\hline 9 & & 25 & 40 & 54 \\
\hline \multirow[t]{6}{*}{10} & & 26 & 41 & 55 \\
\hline & & 27 & 42 & 56 \\
\hline & & 28 & 43 & 57 \\
\hline & & 29 & 44 & 58 \\
\hline & & 30 & 45 & \\
\hline & & 31 & & \\
\hline
\end{tabular}

$\square$ Linha

- Parcela amostrada

Figura 1. Localização das parcelas amostradas na floresta estacional decidual sobre afloramento calcário, no município de São Domingos, GO, bacia do rio Paranã.

Em cada parcela foram amostrados todos os indivíduos arbóreo-arbustivos, vivos ou mortos em pé, com diâmetro à altura do peito ou a $1,3 \mathrm{~m}$ do solo (DAP) igual ou maior que $5 \mathrm{~cm}$, onde foram medidos o DAP e a altura, e identificada a espécie. Os indivíduos perfilhados acima do solo e abaixo do DAP foram incluídos quando as ramificações obedeciam ao critério de inclusão (DAP). Os indivíduos foram marcados com plaquetas de alumínio, numerados e identificados pelo nome científico e, quando não identificados, foram coletados para posterior identificação, anotando-se as características dendrológicas, tais como: cor da casca externa e interna, presença de látex e aroma, para auxiliar na identificação. As espécies foram identificadas com a ajuda de especialistas e comparação em herbário e bibliografia. As exsicatas com estruturas férteis foram depositadas no herbário da Embrapa Recursos Genéticos e Biotecnologia (CEN).

Os parâmetros da estrutura fitossociológica da comunidade foram obtidos de acordo com Mueller-Dombois \& Ellenberg (1974). Os índices de diversidade de Shannon ( $\left.\mathrm{H}^{\prime}\right)$ e a Equabilidade ( $\mathrm{J}$ ') foram calculados conforme Magurran (1988).

\section{Resultados e discussão}

No levantamento fitossociológico foram amostrados 588 indivíduos, dos quais 52 $(8,84 \%)$ mortos ainda em pé. Os indivíduos amostrados correspondem a 21 famílias, 31 gêneros e 36 espécies (Tab. 1), com densidade de 536 indivíduos vivos/ha e área basal de $8,45 \mathrm{~m}^{2} /$ ha. Algumas espécies não puderam ser identificadas devido a ausência de material reprodutivo na época da amostragem.

As famílias com maior riqueza foram Apocynaceae, Bombacaceae, Euphorbiacae e Moraceae, com três espécies cada. As famílias com maior número de indivíduos foram Apocynaceae (20,5\%), Bignoniaceae $(17,7 \%)$, Fabaceae $(9,1 \%)$, Anacardiaceae $(6,9 \%)$ e Euphorbiaceae $(6,9 \%)$ correspondendo a aproximadamente $61 \%$ dos indivíduos amostrados. O destaque para as famílias Apocynaceae e Bignoniaceae foi devido, principalmente, à elevada quantidade de indivíduos de Aspidosperma pyrifolium (76) e Tabebuia impetiginosa (74), sendo, porém, notável a quantidade de espécies $(19,4 \%)$ com um indivíduo amostrado. 
Tabela 1. Relação das espécies amostradas no levantamento da estrutura da comunidade arbórea, em uma floresta estacional decidual sobre afloramento calcário no município de São Domingos, GO, Bacia do Rio Paranã, em ordem alfabética de família.

\begin{tabular}{|c|c|c|}
\hline Família & Nome científico & Nome popular \\
\hline ANACARDIACEAE & Myracrodruon urundeuva Fr. All. & Aroeira \\
\hline APOCYNACEAE & $\begin{array}{l}\text { Aspidosperma cuspa (Kunth) S.F. Blake } \\
\text { A. pyrifolium Mart. } \\
\text { Aspidosperma } \text { sp. }\end{array}$ & $\begin{array}{l}\text { Pereiro } \\
\text { Peroba } \\
\text { Pereiro rabo de tatu }\end{array}$ \\
\hline BIGNONIACEAE & $\begin{array}{l}\text { Jacaranda brasiliana (Lam.) Pers. } \\
\text { Tabebuia impetiginosa (Mart.) Standl. }\end{array}$ & $\begin{array}{l}\text { Caroba } \\
\text { Ipê }\end{array}$ \\
\hline BORAGINACEAE & Cordia glabrata (Mart.) DC. & Cordia \\
\hline BOMBACACEAE & $\begin{array}{l}\text { Chorisia pubiflora (A. St. Hil.) Dawson. } \\
\text { Pseudobombax longiflorum (Mart. \& Zucc.) A. Robyns } \\
\text { P. tomentosum (Mart. \& Zucc.) A. Robyns }\end{array}$ & $\begin{array}{l}\text { Barrigudinha } \\
\text { Canudeiro } \\
\text { Imbiruçú }\end{array}$ \\
\hline BURSERACEAE & $\begin{array}{l}\text { Commiphora leptophloeos (Mart.) Gillet } \\
\text { Commiphora sp. }\end{array}$ & $\begin{array}{l}\text { Cambão } \\
\text { Falsa-cerejeira }\end{array}$ \\
\hline CECROPIACEAE & Cecropia saxatilis Snethlage & Embaúba \\
\hline CELASTRACEAE & Maytenus ilicifolia Mart. ex. Reiss. & Espinheira-santa \\
\hline COMBRETACEAE & Combretum duarteanum Camb. & Vaqueta \\
\hline EUPHORBIACEAE & $\begin{array}{l}\text { Piranhea securinega Radcl-Sm. \& Ratter } \\
\text { Jatropha } \mathrm{sp.} \\
\text { Sapium } \mathrm{sp} .\end{array}$ & Trifoliolada \\
\hline FABACEAE & $\begin{array}{l}\text { Luetzelburgia sp. } \\
\text { Machaerium angustifolium Vog. }\end{array}$ & $\begin{array}{l}\text { Cabeludinha } \\
\text { Jacarandá-de-espinho }\end{array}$ \\
\hline FLACOURTIACEAE & Casearia rupestris Eichler & Maria-mole \\
\hline MELIACEAE & Cabralea canjerana (Vell.) Mart. & Canjerana \\
\hline MIMOSACEAE & Anadenanthera peregrina (L.) Speg. & Angico \\
\hline MORACEAE & $\begin{array}{l}\text { Ficus insipida Willd. } \\
\text { F. pertusa L.f. } \\
\text { Maclura tinctoria (L.) D. Don ex Steud }\end{array}$ & $\begin{array}{l}\text { Ficus-amarelinho } \\
\text { Ficus-da-folha-miúda } \\
\text { Amoreira }\end{array}$ \\
\hline POLYGONACEAE & Triplaris gardneriana Wedd. & Pau-jaú \\
\hline RUBIACEAE & $\begin{array}{l}\text { Coutarea } \mathrm{sp.} \\
\text { Simira sampaiona (Standl.) Steyerm. }\end{array}$ & \\
\hline SAPINDACEAE & $\begin{array}{l}\text { Dilodendron bipinnatum Radlk. } \\
\text { Magonia pubescens A.St. Hil. }\end{array}$ & $\begin{array}{l}\text { Mamoninha } \\
\text { Tingui }\end{array}$ \\
\hline SIMAROUBACEAE & Simarouba versicolor A.St. Hil. & \\
\hline STERCULIACEAE & $\begin{array}{l}\text { Guazuma ulmifolia Lam. } \\
\text { Sterculia striata A. St. Hil. \& Naud. }\end{array}$ & $\begin{array}{l}\text { Mutamba } \\
\text { Chichá }\end{array}$ \\
\hline TILIACEAE & $\begin{array}{l}\text { Heliocarpus americanus } \mathrm{L} . \\
\text { Luehea divaricata Mart. }\end{array}$ & Açoita-cavalo \\
\hline
\end{tabular}


Embora menos comentada que a diferença entre as florestas tropicais e temperadas, existe notável diferença na riqueza de espécies entre diferentes florestas tropicais. Geralmente, florestas secas são menos diversas em espécies que as florestas úmidas (Gentry 1988). Florestas secas, tipicamente, têm cerca de 50-70 espécies $>2,5 \mathrm{~cm}$ de diâmetro, comparado com 150-200 espécies das florestas úmidas sempre-verdes e 200-250 em florestas fluviais, em amostras de 0,1 ha (Gentry 1995). A média de 64,9 espécies de 23 amostras de florestas secas neotropicais de terras baixas (Gentry 1995) está muito acima das 36 espécies encontradas no afloramento calcário amostrado, porém dentro da amplitude (21-81 espécies) listada por esse autor. Exceto para os locais mais áridos, dominados por uma espécie, não há mudança na diversidade das florestas secas com a precipitação (Gentry 1995). O afloramento calcário amostrado tem menos espécies que as áreas planas de floresta seca dessa região amostrada (Tab. 2), decorrência direta do substrato e não da precipitação, que é idêntica devido à proximidade entre as áreas.

O índice de diversidade de Shannon (H') de 2,99, é muito próximo aos valores encontrados em outras três áreas de floresta estacional decidual planas da região (Tab. 2), onde foram utilizadas a mesma metodologia
(Scariot \& Sevilha 2000). Entretanto, o valor de Equabilidade (J') de 0,83, está acima dos valores dessas três áreas planas (Tab. 2), indicando que nesta área de afloramento calcário a distribuição espacial é mais uniforme que nas áreas planas.

As espécies mais abundantes foram Aspidosperma pyrifolium, Combretum duarteanum, Luetzelburgia sp., Myracrodruon urundeuva e Tabebuia impetiginosa, que correspondem a $45 \%$ do número total de indivíduos amostrados.

As florestas secas sobre afloramentos de calcário, apesar de possuírem espécies em comum com outras áreas de afloramento, apresentam composição florística peculiar e fisionomias bem diferenciadas (Pedralli 1997). As florestas sobre solos derivados de calcário exibem algumas espécies importantes, entre as quais destacam-se as que são raras, as ameaçadas de extinção e as de importância econômica, tais como: Cariniana estrellensis, Erythrina verna, Hymenaea courbaril, Myracrodruon urundeuva, Tabebuia impetiginosa (Mecenas et al. 1996), Amburana cearensis, Cedrela fissilis etc.

Foram encontrados 52 indivíduos mortos, correspondendo a $8,8 \%$ dos indivíduos amostrados, os quais foram incluídos em uma única categoria, não sendo possível a distinção das espécies. Como ocorrem em $72 \%$ das

Tabela 2. Parâmetros fitossociológicos registrados em áreas de floresta estacional decidual.

\begin{tabular}{|c|c|c|c|c|c|c|}
\hline Referência & Localidade & 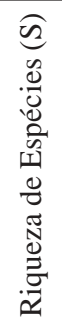 & 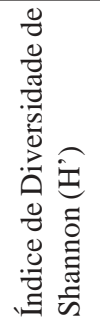 & 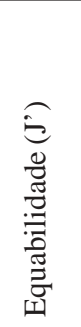 & 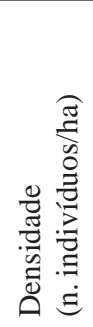 & 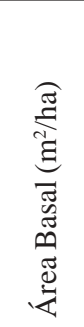 \\
\hline Este trabalho & São Domingos, GO & 36 & 2,99 & 0,83 & 536 & 8,45 \\
\hline Scariot \& Sevilha (2000) & São Domingos, GO (Fazenda São Domingos) & 44 & 2,98 & 0,79 & 591 & 23,17 \\
\hline Scariot \& Sevilha (2000) & São Domingos, GO (Fazenda Flor Ermo) & 48 & 3,03 & 0,78 & 674 & 24,54 \\
\hline Scariot \& Sevilha (2000) & São Domingos, GO (Fazenda Traçadal) & 48 & 2,99 & 0,77 & 688 & 28,34 \\
\hline Ivanauskas \& Rodrigues (2000) & Piracicaba, SP & 54 & 3,00 & 0,70 & 2176 & 29,7 \\
\hline
\end{tabular}


parcelas, isto indica que não está ocorrendo perturbação localizada.

Excluindo os indivíduos mortos, 12 espécies contribuíram com aproximadamente $73 \%$ da soma total do VI (Tab. 3), indicando a predominância de Tabebuia impetiginosa
(43,81), Aspidosperma pyrifolium $(35,64)$, Luetzelburgia sp. (21,77), Commiphora leptophloeos $(18,79)$, Myracrodruon urundeuva (15,79), Pseudobombax tomentosum $(13,42)$, Combretum duarteanum $(13,04)$, Luehea divaricata $(12,24)$, Cabralea

Tabela 3. Parâmetros fitossociológicos das espécies amostradas da comunidade arbórea em uma floresta estacional decidual sobre afloramento calcário no município de São Domingos, GO, Bacia do Rio Paranã. (ni = número de indivíduos, $\mathrm{NA}=$ número de parcelas em que a espécie está presente, $\mathrm{FA}=$ frequiência absoluta $(\%), \mathrm{FR}=$ frequiência relativa (\%), DA = densidade absoluta (ind./ha), DR = densidade relativa (\%), DoA = dominância absoluta ( $\left.\mathrm{m}^{2} / \mathrm{ha}\right), \mathrm{DoR}$ = dominância relativa $(\%), \mathrm{VI}=$ valor de importância, $\mathrm{VC}=$ valor de cobertura).

\begin{tabular}{|c|c|c|c|c|c|c|c|c|c|c|}
\hline Espécie & ni & NA & FA & FR & DA & DR & DoA & DoR & VI & $\mathrm{VC}$ \\
\hline Tabebuia impetiginosa & 74 & 20 & 80,00 & 8,33 & 74,00 & 13,81 & 1,83 & 21,67 & 43,81 & 35,47 \\
\hline Aspidosperma pyrifolium & 76 & 20 & 80,00 & 8,33 & 76,00 & 14,18 & 1,11 & 13,12 & 35,64 & 27,30 \\
\hline Luetzelburgia sp. & 47 & 17 & 68,00 & 7,08 & 47,00 & 8,77 & 0,50 & 5,92 & 21,77 & 14,69 \\
\hline Commiphora leptophloeos & 22 & 11 & 44,00 & 4,58 & 22,00 & 4,10 & 0,85 & 10,10 & 18,79 & 14,21 \\
\hline Myracrodruon urundeuva & 37 & 12 & 48,00 & 5,00 & 37,00 & 6,90 & 0,33 & 3,89 & 15,79 & 10,79 \\
\hline Pseudobombax tomentosum & 16 & 11 & 44,00 & 4,58 & 16,00 & 2,99 & 0,49 & 5,85 & 13,42 & 8,84 \\
\hline Combretum duarteanum & 30 & 14 & 56,00 & 5,83 & 30,00 & 5,60 & 0,14 & 1,61 & 13,04 & 7,20 \\
\hline Luehea divaricata & 25 & 14 & 56,00 & 5,83 & 25,00 & 4,66 & 0,15 & 1,74 & 12,24 & 6,40 \\
\hline Cabralea canjerana & 22 & 10 & 40,00 & 4,17 & 22,00 & 4,10 & 0,31 & 3,72 & 11,99 & 7,83 \\
\hline Ficus pertusa & 11 & 9 & 36,00 & 3,75 & 11,00 & 2,05 & 0,51 & 6,02 & 11,82 & 8,07 \\
\hline Jacaranda brasiliana & 21 & 9 & 36,00 & 3,75 & 21,00 & 3,92 & 0,34 & 4,01 & 11,68 & 7,93 \\
\hline Aspidosperma sp. & 20 & 12 & 48,00 & 5,00 & 20,00 & 3,73 & 0,16 & 1,84 & 10,57 & 5,57 \\
\hline Dilodendron bipinnatum & 20 & 9 & 36,00 & 3,75 & 20,00 & 3,73 & 0,12 & 1 , & 8, & 5,11 \\
\hline Piranhea securinega & 15 & 11 & 44,00 & 4,58 & 15, & 2,80 & 0,08 & 0,89 & 8, & 3,69 \\
\hline Ficus insipida & 8 & 5 & 20,00 & 2,08 & 8,00 & 1,49 & 0, & 4,43 & 8,00 & 5,92 \\
\hline Jatropha sp. & 14 & 8 & 32,00 & 3,33 & 14,00 & 2,61 & 0,0 & 0,46 & 6,40 & 3,07 \\
\hline Aspidosperma cuspa & 14 & 6 & 24,00 & 2,50 & 14, & 2,6 & 0, & 1 , & 6, & 3,75 \\
\hline Cordia glabrata & 10 & 3 & 12,0 & 1,25 & 10 & 1,8 & 0,2 & 3 , & 6,14 & 4,89 \\
\hline Maytenus ilicifolia & 13 & 5 & 20,0 & 2,08 & 13 & 2,43 & 0,0 & 0, & 5,41 & 3,33 \\
\hline Sapium sp. & 8 & 6 & 24,0 & 2,50 & & 1,49 & 3 & 0,40 & 4,39 & 1,89 \\
\hline Chorisia pubiflora & 3 & 3 & 12,00 & 1,25 & 3,0 & 0,56 & 0 & 2,13 & 3,94 & 2,69 \\
\hline Commiphora sp. & 4 & 3 & 12,00 & 1,25 & 4,0 & 0,75 & 0 & 1,7 & 3,72 & 2,47 \\
\hline Anadenanthera peregrina & 4 & 4 & 16,0 & 1,67 & $4,($ & 0,7 & 0 & 0,69 & 3 , & 1,43 \\
\hline Simarouba versicolor & 2 & 2 & & 0, & 2, & 0,3 & & 0 & 1, & 1,10 \\
\hline Simira sampaiona & 4 & 2 & 8 & 0,8 & 4 & 0,7 & & 0,27 & 1,8 & 1,01 \\
\hline Triplaris \& & 3 & 2 & & & & & & & 1 , & 0,96 \\
\hline Machaeriun & 2 & 2 & & & & & & & 57 & 0,73 \\
\hline Cecropia saxatilis & 2 & 2 & & & & & & & 1 , & 0,60 \\
\hline Guazuma ulmifolia & 2 & 1 & 4,0 & & & & & & & 0,64 \\
\hline Sterculia striata & 1 & 1 & & & & & & & 1, & 0,60 \\
\hline Magonia pubescens & 1 & 1 & 4,00 & 0,42 & 1,00 & 0,19 & 0,03 & 0,39 & 1,00 & 0,58 \\
\hline Pseudobombax longiflorum & 1 & 1 & 4,00 & 0,42 & 1,00 & 0,19 & 0,01 & 0,13 & 0,74 & 0,32 \\
\hline Casearia rupestris & 1 & 1 & 4,00 & 0,42 & 1,00 & 0,19 & 0,00 & 0,04 & 0,65 & 0,23 \\
\hline Maclura tinctoria & 1 & 1 & 4,00 & 0,42 & 1,00 & 0,19 & 0,00 & 0,04 & 0,64 & 0,23 \\
\hline Coutarea sp. & 1 & 1 & 4,00 & 0,42 & 1,00 & 0,19 & 0,00 & 0,03 & 0,64 & 0,22 \\
\hline Heliocarpus americanus & 1 & 1 & 4,00 & 0,42 & 1,00 & 0,19 & 0,00 & 0,03 & 0,63 & 0,22 \\
\hline Total & 536 & & 960,00 & 100,00 & 536,00 & 100,00 & 8,45 & 100,00 & 300,00 & 200,00 \\
\hline
\end{tabular}


canjerana (11,99), Ficus pertusa $(11,82)$, Jacaranda brasiliana $(11,68)$ e Aspidosperma sp. (10,57), que somaram 73,52\% do VI total, enquanto as 24 espécies restantes somaram $26,48 \%$.

Tabebuia impetiginosa apresentou maior VI principalmente em decorrência de valores elevados de dominância relativa. Já Aspidosperma pyrifolium, com valores de frequiência e densidade relativa próximos aos de Tabebuia impetiginosa, porém, com menor valor de dominância relativa, tem o segundo maior VI. As demais espécies apresentaram valores menores de VI, sendo que variou a percentagem dos valores de freqüência, densidade e dominância relativa entre as espécies.

Considerando o VC, Tabebuia impetiginosa também aparece em primeira posição, principalmente por apresentar alto valor de dominância relativa. Aspidosperma pyrifolium, Luetzelburgia sp., Commiphora leptophloeos, Myracroduon urundeuva e Pseudobombax tomentosum continuaram na mesma posição. Para as demais espécies, as posições alteraram um pouco devido às variações nos valores de densidade e dominância relativa. A espécie Ficus insipida apresentou maior valor de dominância relativa que Aspidosperma sp., ocupando a sua posição.

$\mathrm{Na}$ bacia do Rio Paranã, a maioria dos fragmentos de florestas estacionais deciduais de áreas planas e de encostas foi explorada para remoção de madeiras. Porém, devido à dificuldade na remoção das árvores dos afloramentos calcários, estes ainda estão em bom estado de conservação, embora geralmente estejam em matriz dominada por pastagens. Apesar dessa área ter menor riqueza de espécies de árvores que as florestas deciduais de áreas planas, sua composição própria de espécies realça a importância desse tipo de vegetação para a conservação da biodiversidade. Os resultados do levantamento da estrutura da comunidade, aqui apresentados, são também importantes para a caracterização do fragmento e fornecem subsídios para a adoção de medidas de manejo e conservação de áreas de florestas estacionais deciduais sobre afloramentos de calcários na região da bacia do Rio Paranã.

\section{Agradecimentos}

Ao proprietário da Fazenda São José, Isidoro Campos de Almeida, pela permissão para a realização deste trabalho; ao Benedito Alísio da S. Pereira, Bruno Machado T. Walter e Alexandre Bonesso Sampaio, pela identificação de algumas espécies; ao Anderson de Cássio Sevilha, Nilton F. Barbosa, Cláudio Vieira de Melo e Lírio Vieira de Melo, pelo grande apoio durante a amostragem; ao Pronabio/Probio, Bird/GEF, MMA, CNPq e Embrapa/Cenargen, pelo financiamento do projeto.

\section{Referências bibliográficas}

Andahur, J. P. 2001. Florestas e questões de gestão ambiental na bacia do Rio Paranã. Dissertação de Mestrado. Universidade de Brasília, Brasília.

Bierregaard Jr., R. O. T.; Lovejoy, V.; Kapos, A. S. \& Hutchings, R. 1992. The biological dynamics of tropical rain forest fragments. BioScience 42: 859-866.

Gentry, A. H. 1995. Diversity and floristic composition of neotropical dry forests. pp. 146-194. In: S. H. Bullock, H. A. Mooney \& E. Medina, (eds.). Seasonally dry tropical forests. Cambridge University Press, Cambridge.

Gentry, A. H. 1988 Changes in plant community diversity and floristic composition on environmental and geographical gradients. Annals of the Missouri Botanical Garden 75: $1-34$.

IBGE. Fundação Instituto Brasileiro de Geografia e Estatística. 1995. Zoneamento ambiental e agroecológico do Estado de Goiás: região nordeste. Rio de Janeiro: IBGE/Divisão de Geociências do Centro-Oeste. (Estudos e pesquisas em geociências, n. 3).

Ivanauskas, N. M. \& Rodrigues, R. R. 2000. Florística e fitossociologia de remanescentes de floresta estacional decidual em Piracicaba, São Paulo, Brasil. Revista Brasileira de Botânica 23(3): 291-304. 
Luíz, G. C. 1998. Estudo do impacto ambiental a partir da análise espaço-temporal - caso da região Vão do Paranã - GO. Dissertação de Mestrado. Universidade Federal de Goiânia, Goiânia.

Maass, J. M. 1995. Conversion of tropical dry forest to pasture and agriculture. Pp. 399-422. In: S. H. Bullock, H. A. Mooney \& E. Medina (eds.). Seasonally dry tropical forests. Cambridge University Press, Cambridge.

Magurran, E. A. 1988. Ecological diversity and its measurement. Princeton University Press, Princeton.

Mecenas, V. V.; Leite, F. Q. \& Cardoso, E. S. 1996. Composição florística de florestas sobre solo calcário, na área de proteção ambiental (APA) de Cafuringa, Brasília - DF. Pp. 326-327. In: $4^{\circ}$ Simpósio Internacional sobre Ecossistemas Florestais - Forest'96, Belo Horizonte, MG.

Mueller-Dombois, D. \& Ellenberg, H. 1974. Aims and methods of vegetation ecology. John Wiley \& Sons, New York.

Pedersoli, J. L. \& Martins, J. L. 1972. A vegetação dos afloramentos de calcário. Oreades 5: 27-29.

Pedralli, G. 1997. Florestas secas sobre afloramentos de calcário em Minas Gerais: florística e fisionomia. Bios 5(5): 81-88.

Pereira, B. A. S.; Mecenas, V. V.; Leite, F. Q. \& Cardoso, E. S. 1996. APA da Cafuringa: o retrato do cerrado. Paralelo 15 editores, Brasília.
Ramos, P. C. M. 1989. Estudos fitossociológicos em uma floresta mesofítica semidecídua na Fercal, Brasília - DF. Dissertação de Mestrado. Universidade de Brasília, Brasília.

Ribeiro, J. F. \& Walter, B. M. T. 1998. Fitofisionomias do bioma cerrado. pp. 85-166. In: Cerrado: ambiente e flora. EMBRAPA-CPAC, Planaltina.

Rizzini, C. T. 1979. Tratado de fitogeografia do Brasil. Hucitec, São Paulo.

Rodrigues, R. R. 1999. A vegetação de Piracicaba e municípios do entorno. IPEF, Circular Técnica, n.189.

Scariot, A. \& Sevilha, A. C. 2000. Diversidade, estrutura e manejo de florestas deciduais e as estratégias para a conservação. pp. 183-188. In. T. B. Cavalcanti \& B. M. T. Walter. Tópicos Atuais em Botânica, Brasília, DF.

Veloso, H. P.; Rangel Filho, A. L. R. \& Lima, J. C. A. 1991. Classificação da vegetação brasileira adaptada a um sistema universal. IBGE, Departamento de Recursos Naturais e Estudos Ambientais, Rio de Janeiro.

Whitmore, T. C. 1997. Tropical forest disturbance, disappearance, and species loss. Pp. 3-14. In: W. F. Laurance \& R. O. Bierregaard, Jr. (eds.). Tropical Forest Remnants: Ecology, Management, and Conservation of Fragmented Communities. The University of Chicago Press, Chicago. 